\title{
Prevalence of Pseudomonas in dental unit water of private dental clinics and its antimicrobial susceptibility using MAR index
}

\author{
Karthik Shunmugavelu, T. Dhanaswathii, S.R. Janani \\ Mercy Multispeciality Dental Centre, Tamilnadu, India
}

\begin{abstract}
The bacteriology of water in a dental unit is important as potentially pathogenic microorganisms like Pseudomonas may be present in dental water unit, which could be fatal for immuno-compromised patients and be of significant morbidity in immuno-competent patients. It is difficult to treat infections caused by Pseudomonas due to their resistance to many commonly used disinfectants and antibiotics. The aim of the present study was to evaluate the Pseudomonas contamination in dental unit water lines of a dental hospital outpatient department and to analyse the antimicrobial susceptibility of Pseudomonas.
\end{abstract}

Keywords: Pseudomonas, dental, pathology, microbiology

\section{INTRODUCTION}

Microorganisms exist primarily by attaching to and growing upon living and inanimate surfaces resulting in biofilm formation. Biofilm formation is a process by which microorganisms irreversibly attach to and grow on a surface and produce extracellular polymeric substance (EPS) that facilitate attachment and matrix formation, resulting in an alteration in the phenotype of the organisms with respect to growth rate and gene transcription (1). Biofilms are seen in oral soft tissues and teeth, middle ear, gastrointestinal tract, urogenital tract, prosthetic heart valves, hip and joint prosthetic replacements, catheters, intrauterine devices, contact lens and dental unit water lines (2).

Dental unit waterlines are an integral part of the dental chair, supplying water as a coolant for air-turbines and ultrasonic scalar and are susceptible to biofilm formation. The bacteriology of water in a dental unit is important as potentially pathogenic microorganisms may be present in dental unit water which could be fatal for immuno-com- promised patients and be of significant morbidity in immuno-competent patients (4). The contamination is also of considerable importance to dental professionals. The wide range of microorganisms includes gram positive bacteria such as Streptococcus, Staphylococcus, Mycobacterium and Actinomycetes; gram negative bacteria such as Pseudomonas, Escherichia coli, Klebsiella and Legionella; yeast particularly, Candida; protozoa such as Acanthamoeba, Cryptosporidium and viruses particularly hepatitis $\mathrm{B}$ surface antigen $(3,4,23)$.

It has been reported that most of the bacteria isolated from dental unit water lines are gram negative, heterotrophic bacteria. Pseudomonas is the most prevalent among the gram negative bacteria isolated from dental unit water and shown to cause nosocomial infection $(14,15,19)$. Pseudomonas are aerobic, gram negative, motile bacilli. It is difficult to treat infections caused by Pseudomonas due to their resistance to many commonly used disinfectants and antibiotics $(5,6)$. High prevalence of multiple antibiotic resistance indicates a serious need 
for surveillance and planning of effective interventions in such pathogens. In 1983, Krumperman described the Multiple Antibiotic Resistance (MAR) index as a good tool for health risk assessment. It is calculated as the ratio of number of antibiotics to which test isolate is resistant to total number of antibiotics to which the test isolate is exposed. MAR index values greater than 0.2 indicate high risk source of contamination where antibiotics are often used $(7,8)$.

\section{AIM}

The aim of our study was to find the prevalence of pseudomonas in dental unit water. The objective of the study was to evaluate the presence of Pseudomonas contamination of dental unit water and to analyse the antimicrobial susceptibility of pseudomonas isolated from dental unit water using MAR index.

\section{MATERIALS AND METHODS}

This cross sectional study was conducted in ten private dental clinics. Water samples were collected from 10 dental clinics in different clinical specialities. Inclusion criteria included dental units that were in daily use for approximately a year.

\section{Collection of samples}

All water samples were collected from the air/ water syringe (3 way syringe) using sterile technique. The sterile technique includes use of sterile gloves, wiping the external surface of air/ water syringe with $70 \%$ alcohol to prevent contamination and collection of sample in a sterile container. Water samples were collected in the mid-day and the lines were flushed for 20 seconds after which $20 \mathrm{ml}$ water was collected. Water splashing was minimised when filling the container and any contact between the air/ water syringe and the container was avoided. The water samples were labelled containing details of dental unit, department, date and time.

\section{Transport of water samples}

All the water samples in sterile containers were immediately transferred to the laboratory and processed for microbial evaluation.

\section{Culture of water samples}

Each water sample was centrifuged and $0.1 \mathrm{ml}$ of the sediment was taken and then inoculated in Petri plates using streak method on the following culture media - nutrient agar (basal medium), MacConkey agar (differentiating medium), Blood agar (enriched medium) and Cetrimide agar (selective medium) (High-Media Laboratories). It was incubated at $37^{\circ} \mathrm{C}$ for 24 hours.

\section{Isolation and identification}

The plates were observed for growth. The isolated pathogens were identified for the presence of Pseudomonas on the basis of colony morphology, pigmentation, Gram staining and biochemical characteristics. The colony morphology that was noted for the presence of Pseudomonas were pearlescent appearance, grape like odour and yellow green pigmentation on cetrimide agar. Gram smear was done and gram negative rods were noted (Figure 1). Biochemical tests such as oxidase tests and catalase tests were done for confirmation (5).

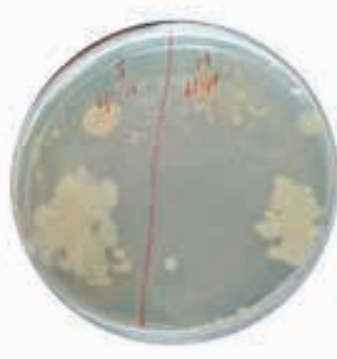

A

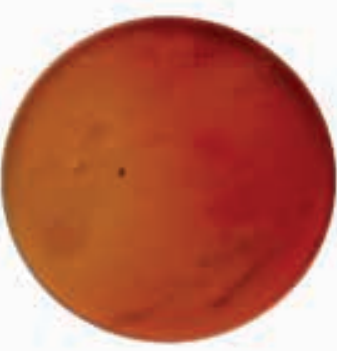

B
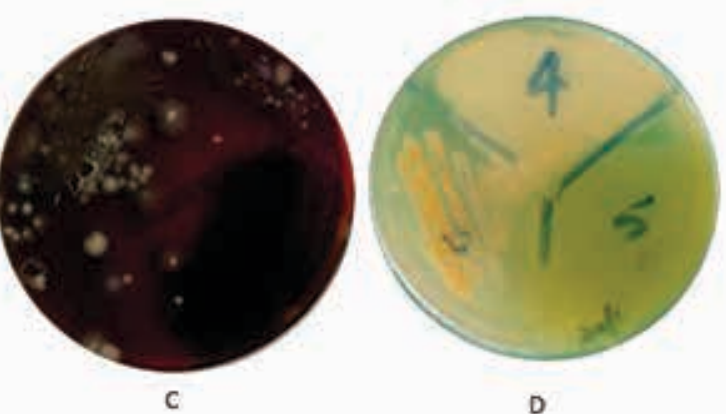

D

FIGURE 1. Colony morphology in various agar. $A$ - Nutrient agar; $B$ - MacConkey agar; $C$ - Blood agar; $D$ - Cetrimide agar 


\section{Antibiotic sensitivity tests}

All the confirmed Pseudomonas isolates were subsequently tested for antibiotic sensitivity patterns. Lawn culture was prepared on Mueller Hinton agar. The antibiotic sensitivity pattern was tested using agar diffusion (Kirby Bauer disc diffusion) method using nine different antibiotics discs (Clairo (R Combi GN1) (Table 1). The antibiotics used were specifically anti-pseudomonal: Norfloxacin, Aztreonam, Cefotaxime, Gentamycin, Amikacin, Ciprofloxacin, Ofloxacin, Ceftazidime and Cefdinir.

TABLE 1. Antibiotics used in the study

\begin{tabular}{|l|c|}
\hline ANTIBIOTICS & $\begin{array}{c}\text { CONCENTRATION } \\
\text { (mcg) }\end{array}$ \\
\hline Norfloxacin & 10 \\
\hline Aztreonam & 30 \\
\hline Cefotaxime & 30 \\
\hline Gentamycin & 10 \\
\hline Amikacin & 30 \\
\hline Ciprofloxacin & 5 \\
\hline Ofloxacin & 5 \\
\hline Ceftazidime & 30 \\
\hline Cefdinir & 5 \\
\hline
\end{tabular}

Zone of inhibition was measured in millimetre $(\mathrm{mm})$ using HiAntibiotic Zone scale (HiMedia Laboratory) to define sensitivity or resistance to different antibiotics. The risk assessment was done using Multiple Antibiotic Resistance (MAR) index determination for each isolate as described by Krumperman (1983). MAR index is calculated using the following formula (7):

MAR index $=$ Number of antibiotics to which test isolate depicted resistance/total number of antibiotics used

\section{RESULTS}

\section{Isolation and identification}

Based on colony morphology observed on culture media, gram staining and biochemical tests, Pseudomonas was identified and isolated (Table 2). A total of 10 dental unit water samples were collected and assessed for Pseudomonas contamination. Out of these, 8 water samples ( $80 \%$ ) were positive for Pseudomonas, one sample (10\%) had no significant growth and one sample (10\%) was suggestive of E coli.

\section{Antibiotic susceptibility by Pseudomonas}

Out of eight, seven isolates (87.5\%) of Pseudomonas showed susceptibility to Norfloxacin fol- lowed by Amikacin (six isolates). Out of eight, seven isolates (87\%) of Pseudomonas showed high level of resistance to Ciprofloxacin and Cefdinir followed by Aztreonam, Ofloxacin and Ceftazidime (six isolates; 85.7\%) (Table 3).

TABLE 3. Antibiotic susceptibility of Pseudomonas isolates from 8 samples

\begin{tabular}{|l|c|c|}
\hline ANTIBIOTICS & Resistant isolates & Sensitive isolates \\
\hline Norfloxacin & 1 & 7 \\
\hline Aztreonam & 6 & 2 \\
\hline Cefotaxime & 4 & 4 \\
\hline Gentamycin & 4 & 4 \\
\hline Amikacin & 2 & 6 \\
\hline Ciprofloxacin & 7 & 1 \\
\hline Ofloxacin & 6 & 2 \\
\hline Ceftazidime & 6 & 2 \\
\hline Cefdinir & 7 & 1 \\
\hline
\end{tabular}

\section{Risk assessment using MAR index}

The multiple antibiotic resistance indices were higher than the 0.2 limit in 7 out of 8 isolates $(87.5 \%)$, indicating the high risk source of contamination in dental unit water (Table 4 and figure 2).

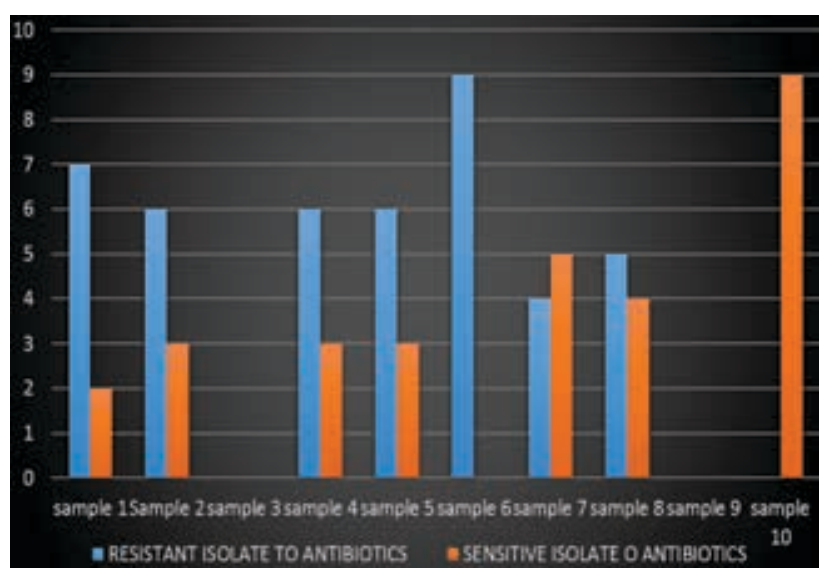

FIGURE 2. Antibiotic susceptibility of Pseudomonas isolates from 8 samples

TABLE 4. Antibiotic resistance profile and multiple antibiotic resistance (MAR) index of Pseudomonas isolates of each sample

\begin{tabular}{|c|c|c|c|c|}
\hline Sample & $\begin{array}{c}\text { Resistant } \\
\text { isolate }\end{array}$ & \begin{tabular}{|c} 
Sensitive \\
isolate
\end{tabular} & $\begin{array}{l}\text { MAR } \\
\text { Index }\end{array}$ & Inference $(<0.2)$ \\
\hline 1 & 7 & 2 & 0.7 & High risk \\
\hline 2 & 6 & 3 & 0.6 & High risk \\
\hline 3 & - & - & - & - \\
\hline 4 & 6 & 3 & 0.6 & High risk \\
\hline 5 & 6 & 3 & 0.6 & High risk \\
\hline 6 & 9 & 0 & 1 & High risk \\
\hline 7 & 4 & 5 & 0.4 & High risk \\
\hline 8 & 5 & 4 & 0.5 & High risk \\
\hline 9 & - & - & - & - \\
\hline 10 & 0 & 9 & 0 & Low risk \\
\hline
\end{tabular}




\begin{tabular}{|c|c|c|c|c|c|c|c|c|c|c|}
\hline$\frac{\breve{m}}{\check{c}}$ & 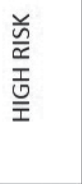 & 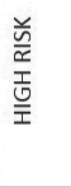 & & 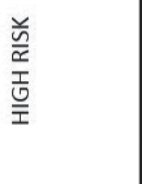 & $\begin{array}{l}\frac{\breve{M}}{\bar{x}} \\
\frac{I}{\underline{J}} \\
\frac{\underline{I}}{I}\end{array}$ & 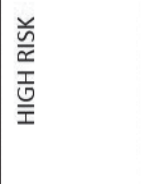 & 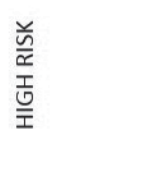 & 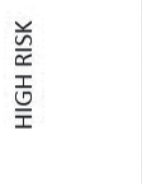 & & 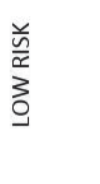 \\
\hline 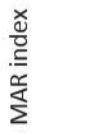 & $\hat{o}$ & $\stackrel{\circ}{\circ}$ & ' & $\stackrel{\circ}{\circ}$ & $\stackrel{\circ}{\circ}$ & -1 & ¿̊. & น? & ' & 0 \\
\hline 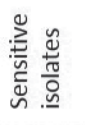 & $\sim$ & $m$ & ' & $m$ & $m$ & 0 & in & $\nabla$ & ' & $\sigma$ \\
\hline 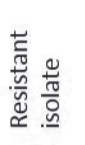 & - & 0 & ' & 6 & 0 & $a$ & $\sigma$ & in & ' & 0 \\
\hline 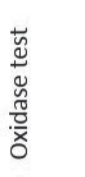 & + & + & 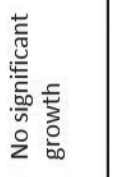 & + & + & + & + & + & 1 & + \\
\hline 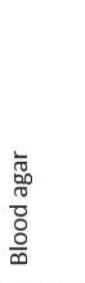 & 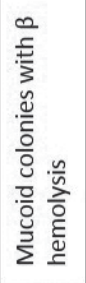 & 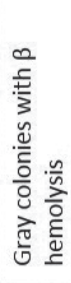 & 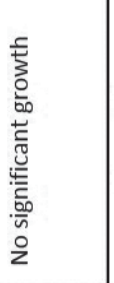 & 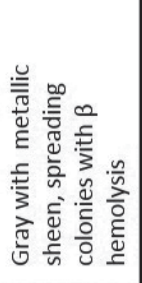 & 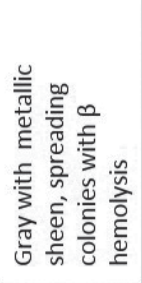 & 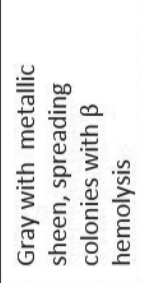 & 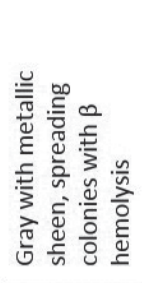 & 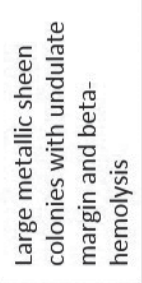 & 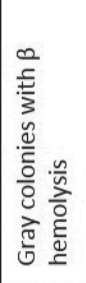 & 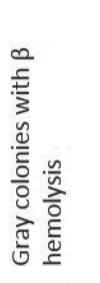 \\
\hline 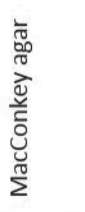 & 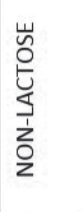 & 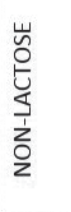 & 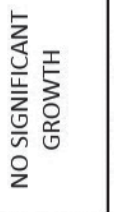 & 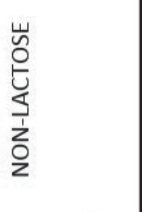 & 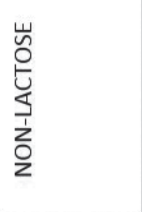 & 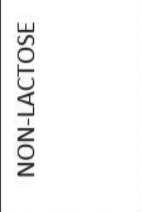 & 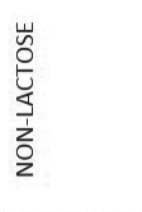 & 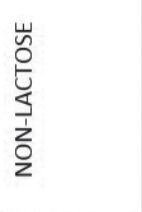 & 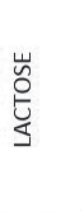 & 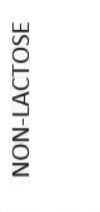 \\
\hline 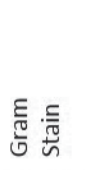 & $\begin{array}{l}\frac{n}{0} \\
\dot{0} \\
\dot{1}\end{array}$ & $\begin{array}{l}\frac{n}{0} \\
\frac{1}{0} \\
0\end{array}$ & $\begin{array}{l}\frac{n}{0} \\
1 \\
\dot{1}\end{array}$ & $\begin{array}{l}\frac{n}{0} \\
\frac{1}{0} \\
0\end{array}$ & $\begin{array}{l}\frac{n}{0} \\
\frac{1}{0}\end{array}$ & $\begin{array}{l}\frac{n}{0} \\
0 \\
1 \\
0\end{array}$ & $\begin{array}{l}\frac{n}{0} \\
\frac{1}{0} \\
\dot{1}\end{array}$ & $\begin{array}{l}\frac{n}{0} \\
\frac{1}{0}\end{array}$ & $\begin{array}{l}\stackrel{n}{0} \\
\dot{0} \\
\dot{1}\end{array}$ & $\begin{array}{l}\frac{n}{0} \\
\dot{0} \\
\dot{1}\end{array}$ \\
\hline 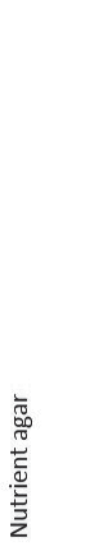 & 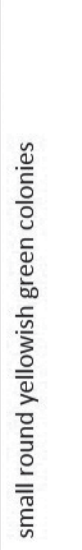 & 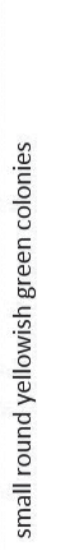 & 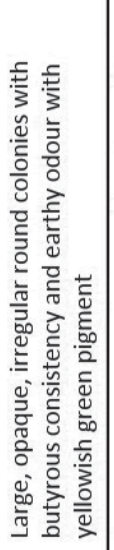 & 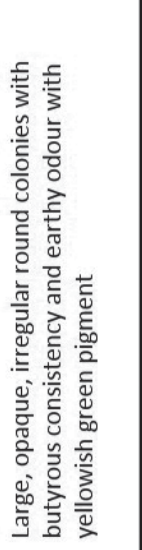 & 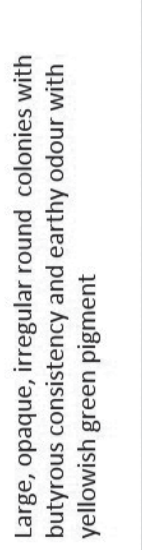 & 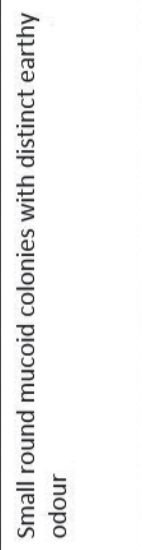 & 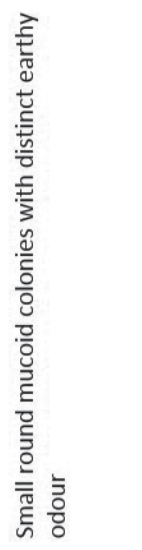 & 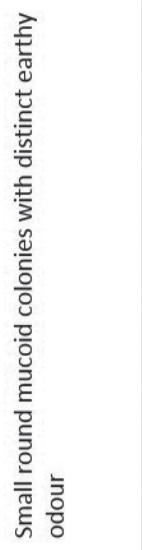 & 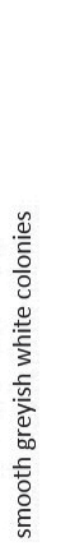 & 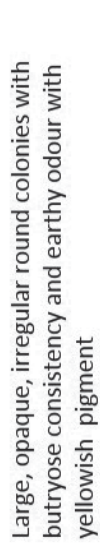 \\
\hline 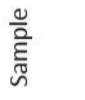 & 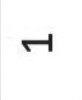 & $N$ & $m$ & $\nabla$ & ம & 6 & $N$ & $\infty$ & $\sigma$ & 암 \\
\hline
\end{tabular}




\section{DISCUSSION}

The results of this study indicate that the water lines of dental unit remain a potential weakness site in control of infection in dental practice. Out of 10 water samples, Pseudomonas was isolated in $80 \%$ of the samples indicating the high risk source of contamination. The high level of Pseudomonas contamination demonstrated in this study confirmed the results of others (8-20). The high level of contamination in dental unit water could originate from two sources: the public water piped into the dental chair (due to narrow lumens and long periods of stagnant water) and suck back of patient's saliva into the line due to lack of anti-retraction valves. Microorganisms present in the oral cavity could be aspirated into the dental unit water lines using defective check valve $(11,12)$.

In contrast, Pseudomonas was not isolated in a study conducted in Shimla. In this study, water samples were collected from air / water syringe of dental unit before and after flushing. Staphylococcus coagulase negative colonies were only demonstrated with no pseudomonas contamination. The climatic conditions in Shimla does not favour the pseudomonas growth in water reservoir (21). In another study, the authors investigated the microbial diversity of biofilms found in dental unit water systems by three methods: microscopic examination by scanning electron microscopy (SEM), acridine orange staining, and fluorescent in situ hybridization (FISH); second method, 55 cultivated biofilm isolates were identified by $16 \mathrm{~S}$ ribosomal DNA (rDNA) sequencing; third method was a culture-independent direct amplification and sequencing of 165 subclones from community biofilm $16 \mathrm{~S}$ rDNA. In this study, prevalence of Pseudomonas (5\%) was comparatively lesser than other bacteria that includes Leptospira (20\%), Sphingomonas (14\%), Bacillus (7\%), Escherichia (6\%) (22).

In the present study, isolates of Pseudomonas showed susceptibility to Norfloxacin followed by Amikacin. This indicates that the drugs Norfloxacin and Amikacin can be used as drug of choice against Pseudomonas infection in dental treatment. However, Ciprofloxacin and Cefdinir which are highly resistant should not be used against infection. Norfloxacin (Fluoroquinolones) acts against pseudomonas by inhibiting the enzyme bacterial
DNA gyrase, which nicks double stranded DNA, introduces negative supercoils and then reseals the nicked ends. Amikacin (Aminoglycosides) binds to $30 \mathrm{~S}$ ribosomes and inhibits protein synthesis. Ciprofloxacin acts similar to Norfloxacin but increased resistance to pseudomonas could be due to mutation in DNA gyrase that has reduced affinity for fluoroquinolone. Cefdinir (Third generation Cephalosporins) acts by inhibiting cell wall synthesis and resistance to cefdinir could be due to loss of permeability to the antibiotic (25).

The Multiple Antibiotic Resistance (MAR) indices were higher than 0.2 limit in 7 out of 8 isolates (Table 4) indicating high risk source of contamination and originate from an environment where many antibiotics are used. This increase in MAR index does not translate the actual contamination; nevertheless, appropriate measures need to be taken.

Various recommendations are put forward to reduce the microbial contamination: Flushing the water lines in between patients and at the beginning and end of the day is a simple and useful method to eliminate oral flora entering the waterlines via suck-back $(19,20)$. Use of disinfectants such as sodium hypochlorite, hydrogen peroxide, Chlorhexidine to flush the dental unit waterlines is an effective method (23). A recent study concluded a newly available product, chlorine dioxide $(\mathrm{ClO} 2)$ as an effective disinfectant against biofilms of dental unit water lines tubing (24). Usage of Anti-retraction valves that are regularly monitored and maintained can be used to reduce contamination from the patient (13). All these systems require a strict adherence to maintenance protocols to perform to their full potential.

\section{CONCLUSIONS}

The result is important and should be considered based on the fact that the Pseudomonas is more prevalent in the water sample. Therefore, it is necessary to regularly monitor microbiological quality of water in dental unit water, including detection of opportunistic pathogens, prevent water stagnation and use various treatment procedures available to disinfect and reduce biofilm formation in dental unit water. 


\section{REFERENCES}

1. Donlan RM. Biofilm formation: a clinically relevant microbiological process. Clinical Infectious Diseases. 2001 Oct 15;33(8):1387-92.

2. Venkatesh VK, Vidyashree NV, Parameswaran A, Kandaswamy D. Evaluation of bacterial contamination of dental unit water lines and the efficacy of a commercially available disinfectant. Journals of Conservative Dentistry. 2006 Jul 1;9(3):93.

3. Costa D, Mercier A, Gravouil K, Lesobre J, Verdon J, Imbert C. Occurrence and diversity of both bacterial and fungal communities in dental unit waterlines subjected to disinfectants. Fems Pathogens and Disease. 2016 Sep 13;74(7):ftw094.

4. Percival SL, Suleman L, Vuotto C, Donelli G. Healthcare-associated infections, medical devices and biofilms: risk, tolerance and control. Journal of Medical Microbiology. 2015 Apr 1;64(4):323-34.

5. Alkhulaifi MM, Alotaibi DH, Alajlan H, Binshoail T. Assessment of nosocomial bacterial contamination in dental unit waterlines: Impact of flushing. The Saudi Dental Journal. 2020 Feb 1;32(2):68-73.

6. Coleman DC, O'Donnell MJ, Shore AC, Russell RJ. Biofilm problems in dental unit water systems and its practical control. Journal of Applied Microbiology. 2009 May;106(5):1424-37.

7. Krumperman PH. Multiple antibiotic resistance indexing of Escherichia coli to identify high-risk sources of fecal contamination of foods. Applied and Environmental Microbiology. $1983 \mathrm{Jul}$ 1;46(1):165-70.

8. Bhuvaneshwari G. Multiple antibiotic resistance indexing of non-fermenting gram-negative bacilli. Asian J Pharm Clin Res. 2017;10(6):78-80.

9. Salam N, Mulamoottil VM, George B. Assessment of Microbial Contamination in Dental-Unit Water Lines: An Analytical Study. Journal of Indian Association of Public Health Dentistry. 2017 Jan 1;15(1):97.

10. Szymańska J, Sitkowska J. Bacterial contamination of dental unit waterlines. Environmental Monitoring and Assessment. 2013 May 1;185(5):3603-11.

11. Barben J, Schmid J. Dental units as infection sources of Pseudomonas aeruginosa. European Respiratory Journal. 2008 Oct 1;32(4):1122-3.

12. Ji XY, Fei CN, Zhang Y, Zhang W, Liu J, Dong J. Evaluation of bacterial contamination of dental unit waterlines and use of a newly designed measurement device to assess retraction of a dental chair unit. International Dental Journal. 2016 Aug;66(4):208-14.

13. Gomashe AV, Gulhane PA, Dharmik PG, Barhanpure AK. Dental unit water lines: The infectious sources of Pseudomonas aeruginosa. Journal of Applied and Natural Science. 2012 Dec 1;4(2):200-3.

Conflict of interest: none declared

Financial support: none declared
14. James A, Shetty A, Hegde MN, Bhandary S. Detection \& Quantification of Microorganisms in Dental Unit Waterlines. J Dent Med Sci. 2015;14:88-91.

15. Pouralibaba F, Balaei E, Kashefimehr A. Evaluation of gram negative bacterial contamination in dental unit water supplies in a university clinic in tabriz, iran. Journal of Dental Research, Dental Clinics, Dental Prospects. 2011;5(3):94.

16. Oliveira AC, Maluta RP, Stella AE, Rigobelo EC, Marin JM, Ávila FA. Isolation of Pseudomonas aeruginosa strains from dental office environments and units in Barretos, state of São Paulo, Brazil, and analysis of their susceptibility to antimicrobial drugs. Brazilian Journal of Microbiology. 2008 Sep;39(3):579-84.

17. Walker JT, Bradshaw DJ, Bennett AM, Fulford MR, Martin MV, Marsh PD. Microbial biofilm formation and contamination of dental-unit water systems in general dental practice. Applied and Environmental Microbiology. 2000 Aug 1;66(8):3363-7.

18. Siang MM, Yunus Z, Yunus AR, Ahmad Z, Toosa H. The microbiological quality of water from dental unit waterlines in Malaysian Armed Forces dental centres. Archives of Orofacial Sciences. 2012 Jan 1;7(1):1-7.

19. Al-Hiyasat AS, Ma'ayeh SY, Hindiyeh MY, Khader YS. The presence of Pseudomonas aeruginosa in the dental unit waterline systems of teaching clinics. International Journal of Dental Hygiene. 2007 Feb;5(1):36-44

20. Tambekar DH, Gulhane PB, Goyal KS, Gulhane SR. Prevalence of Pseudomonas aeruginosa in dental unit water-lines. Res $\mathrm{J}$ Microbiol. 2007;2:983-7.

21. Fotedar S, Ganju S. Microbial contamination of dental unit water lines in HP Government Dental College, Shimla. The Saudi Journal for Dental Research. 2015 July 1;6(2):129-32.

22. Singh R, Stine OC, Smith DL, Spitznagel JK, Labib ME, Williams HN. Microbial diversity of biofilms in dental unit water systems. Applied and Environmental Microbiology. 2003 Jun 1;69(6):3412-20.

23. Barbot V, Robert A, Rodier MH, Imbert C. Update on infectious risks associated with dental unit waterlines. FEMS Immunology \& Medical Microbiology. 2012 Jun 15;65(2):196-204.

24. Patel M, Desai J, Owen PC. The efficacy of disinfectants in the decontamination of dental unit water lines: an in vitro laboratory study. BDJ open. 2016 Feb 26;2:16003.

25. Tuvo B, Totaro M, Cristina ML, Spagnolo AM, Di Cave D, Profeti S, Baggiani A, Privitera G, Casini B. Prevention and Control of Legionella and Pseudomonas spp. Colonization in Dental Units. Pathogens. 2020 Apr;9(4):305. 